\title{
Drug Utilization and Prescribing Pattern of Glaucoma in a Tertiary Care Hospital of Dehradun
}

\author{
Reenoo Jauhari ${ }^{1}$, Vandana ${ }^{2 *}$ \\ ${ }^{1}$ Assistant Professor, Department of Pharmacy Practice, School of Pharmaceutical Sciences, Shri Guru Ram Rai University, Patelnagar, \\ Dehradun-248001, Uttarakhand, India \\ 2 M. Pharm (Pharmacy Practice), Department of Pharmacy Practice, School of Pharmaceutical Sciences, Shri Guru Ram Rai University, \\ Patelnagar, Dehradun-248001, Uttarakhand, India
}

\begin{abstract}
Glaucoma is a condition in which distinctive changes occur in the optic nerve and visual field. In glaucoma intraocular pressure (IOP) is raised that compresses and damages the optic nerve. As the optic nerve is damaged, it fails to carry the visual information to the brain which induce clinically progressive loss of peripheral visual field and ultimately loss of vision. Aims and Objectives: To Evaluate the drug utilization and prescribing pattern of drugs used for treatment of glaucoma, to analyze current prescribing trends in anti-glaucoma drugs, to perform a drug utilization study, to identify drugs per prescription, category wise identification of drugs prescribed, mono therapy vs combination therapy. Materials and Methods: The present study was a prospective, observational study carried out in 105 patients at Shri Mahant Indiresh Hospital, Dehradun, Uttarakhand, India. Results: Out of total 105 patients, 68 were males (64.76\%) and 37 were females (35.24\%). The most common age group was 46-60 years. Patients were mostly affected by primary open angle glaucoma (95.23\%) then angle closer glaucoma (4.76\%). Total 184 drugs were prescribed in the treatment of glaucoma. Average number of drugs per prescription was 1.75 . Combination therapy was prescribed in $51.43 \%$ patients \& most common used combination therapy was combination of Brimonidine+ timolol (81.48\%) followed by Bimatoprost+ timolol (18.52\%). Monotherapy was used in $48.57 \%$ patients in which drug dorzolamide (22.31\%) was prescribed mostly which is belongs to the category of carbonic anhydrase inhibitors followed by timolol (19.23\%) ( $\beta$ - blockers) which was second line choice of drug. Generic drugs were mostly prescribed in 77 patients (73.33\%) followed by 28 patients $(26.66 \%)$ were brand names. Conclusion: The prescription analysis of glaucoma patients concluded that monotherapy with dorzolamide was the first line choice for glaucoma therapy and timolol was found to be the second line choice. Timolol+ brimonidine was the mostly prescribed combination of drug. It also showed that all drugs were prescribed in their generic name instead of brand name.
\end{abstract}

Article Info: Received 10 July 2019; Review Completed 18 Aug 2019; Accepted 23 Aug 2019; Available online 30 Aug 2019

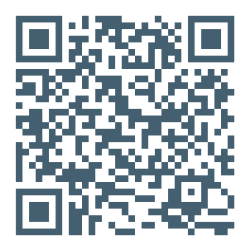

\section{Cite this article as:}

Reenoo J, Vandana, Drug Utilization and Prescribing Pattern of Glaucoma in a Tertiary Care Hospital of Dehradun, Journal of Drug Delivery and Therapeutics. 2019; 9(4-A):497-504 http://dx.doi.org/10.22270/jddt.v9i4-A.3405

\section{*Address for Correspondence:}

Vandana, M. Pharm (Pharmacy Practice), Department of Pharmacy Practice, School of Pharmaceutical Sciences, Shri Guru Ram Rai University, Patelnagar, Dehradun-248001, Uttarakhand, India

\section{INTRODUCTION}

Glaucoma is a condition in which distinctive changes occur in the optic nerve and visual field. It is characterized by raised intraocular pressure (IOP) that compresses and damages the optic nerve. As the optic nerve is damaged, it fails to carry the visual information to the brain which cause clinically progressive loss of peripheral visual field and ultimately loss of vision. [1]

Glaucoma is not a single disease entity but it's a group of eye diseases characterized by anatomical features, such as open angle where the anterior chamber angle of the eye remains open and angle closure where anterior chamber angle remains closed. [2]
There is so many risk factors to cause glaucoma such as, High intraocular pressure, age more than 60 years, family history of glaucoma, systemic conditions like diabetes, heart disease, high blood pressure and sickle cell anemia, eye condition like near sightedness, and topical administration of steroids for a long time. It is difficult to detect optic nerve damage in early stages of the disease. [3]

Treatment of glaucoma depends on the type of disease. It can be treated with eye drops, oral pills, laser, open surgical procedure, or a combination of methods. The whole purpose of treatment is to prevent further loss of vision. This is imperative as loss of vision due to glaucoma is irreversible. Keeping the IOP (intra ocular pressure) under control is the main key factor in preventing the loss of vision from glaucoma. [4] 
Drug therapy is an important component of patient care management in health care settings. Many pharmaceutical products are available in the market often having unaffordable cost. Irrational use of drugs and dosage forms result in potential adverse effects to the patients and cause financial burden. To avoid such problems, every member of the healthcare system should practice rational use of drugs. So, drug utilization study is important criteria to avoid the irrationality of drugs. [5]

Evaluation of drug utilization pattern is considered powerful means to find out the role of drugs in society as well as to increase the therapeutic efficacy and the cost-effectiveness of therapy in medical practices. In addition, periodic auditing of drug utilization pattern also provides feedback to the prescribers and helps to decrease the occurrence of untoward adverse effects due to the use of medicines. [6]

\section{MATERIAL AND METHODS:}

A prospective study was conducted at a tertiary care hospital in Dehradun, Uttarakhand for a duration of 6 months. After getting approval from the ethics committee of the hospital, subjects were selected based on inclusion \& exclusion criteria.

\section{Inclusion criteria:}

$>$ Patients visiting at Outpatient Department of Ophthalmology for the treatment of glaucoma.

$>$ Patients with either sex (male and female).

$>$ Patients more than 18 years of age.

$>$ Patients willing to participate in the study.

\section{Exclusion criteria:}

> Patients not willing to participate in the study.

$>$ Patients less than 18 years of age.

$>$ Patients who are diagnosed with other ophthalmological condition/ surgery.

Signed inform consent was obtained from all participants prior to the study. Data was collected from the patients using self-designed structured data collection form to assess the drug utilization pattern and prescribing pattern of glaucoma medication. Other relevant information on the disease, prevalence, diagnosis, treatment plan was collected.

\section{RESULTS:}

\section{Gender wise distribution of patients}

Out of 105 glaucoma patients, $64.76 \%(n=68)$ were male \& $35.24 \%(n=37)$ were female as shown in table 1 and figure 1.

Table 1: Gender wise distribution of patients

\begin{tabular}{|l|l|}
\hline Category & $\begin{array}{l}\text { Number of patients (\%) } \\
(\mathbf{n = 1 0 5 )}\end{array}$ \\
\hline Male & $68(64.76 \%)$ \\
\hline Female & $37(35.24 \%)$ \\
\hline
\end{tabular}

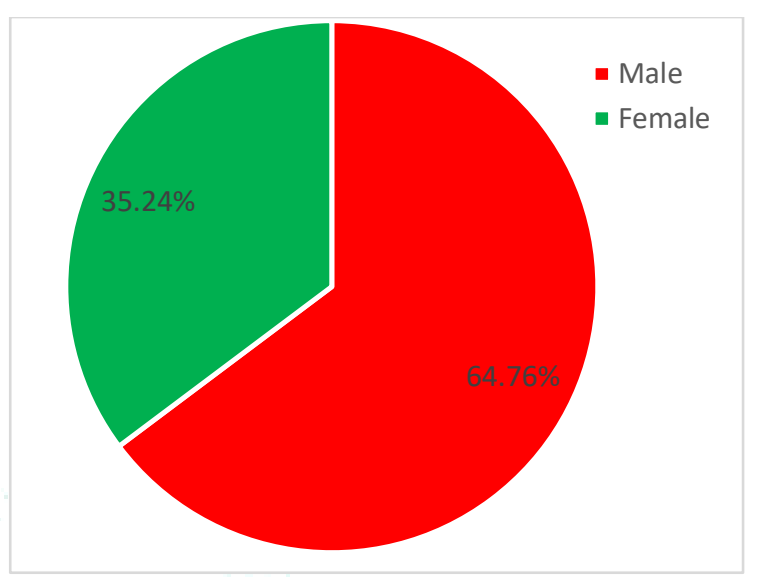

Figure 1: Gender wise distribution of patients

\section{Age wise distribution of patients}

Out of 105 patients, the maximum patients belong to age group between $46-60$ which were $64.76 \%$ as shown in table 2 and figure 2.

Table 2: Age wise distribution of patients

\begin{tabular}{|c|c|}
\hline Age (Years) & $\begin{array}{c}\text { Number of patients (\%) } \\
(\mathbf{n = 1 0 5 )}\end{array}$ \\
\hline $30-45$ & $15(14.28 \%)$ \\
\hline $46-60$ & $68(64.76 \%)$ \\
\hline$>60$ & $22(20.95 \%)$ \\
\hline
\end{tabular}

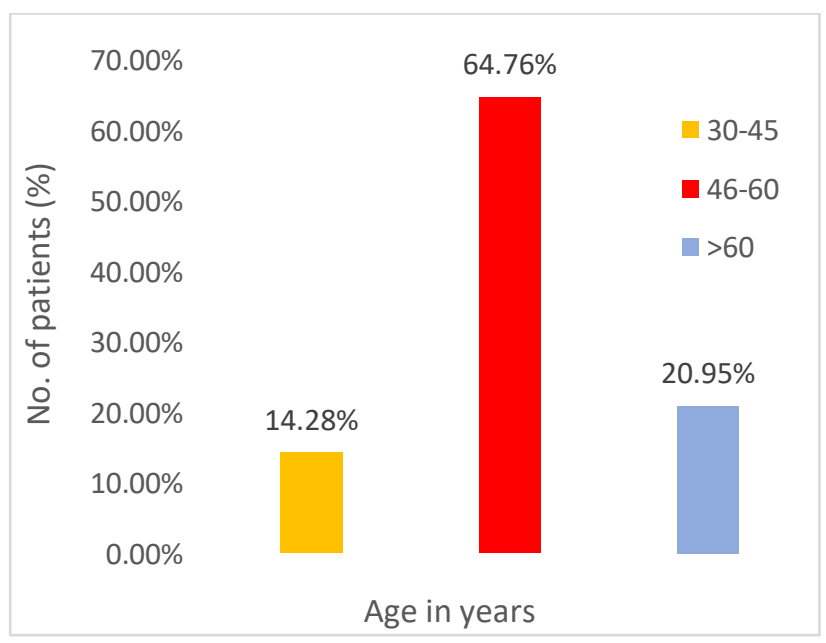

Figure 2: Age wise distribution of patients 


\section{Pattern of glaucoma (n=105 patients)}

Among 105 patients, open angle glaucoma accounted for $95.23 \%(n=100)$ \& Angle closure glaucoma $4.76 \%(n=5)$ as shown in table 3 and figure 3 .

Table 3: Pattern of glaucoma ( $n=105$ patients)

\begin{tabular}{|c|c|c|}
\hline Types of Glaucoma & Frequency & Percentage \\
\hline $\begin{array}{c}\text { Open angle glaucoma- } \\
\text { Primary open angle glaucoma }\end{array}$ & 100 & $95.23 \%$ \\
\hline $\begin{array}{c}\text { Close angle glaucoma- } \\
\text { Angle closure glaucoma }\end{array}$ & 5 & $4.76 \%$ \\
\hline
\end{tabular}

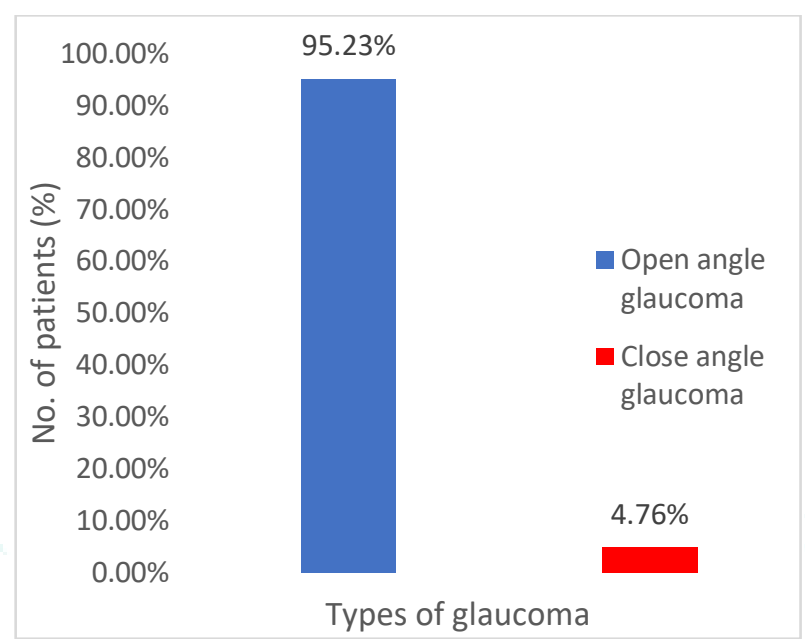

Figure 3: Pattern of glaucoma $(n=105$ patients $)$

\section{Drugs prescribed for glaucoma}

Among 105 patients, total of 184 drugs were prescribed for the treatment of open and close angle glaucoma as shown in table 4 \& figure 4.

Table 4: Drugs prescribed for glaucoma

\begin{tabular}{|l|l|l|l|}
\hline S.No. & Name of Drug & Generic Name & $\begin{array}{l}\text { No. of drugs (\%) } \\
(\mathbf{n = 1 8 4 )}\end{array}$ \\
\hline 1 & Betaxolol & Betaxolol & $3(1.63 \%)$ \\
\hline 2 & Dorzox & Dorzolamide & $29(15.76 \%)$ \\
\hline 3 & Pilocarpine & Pilocarpine & $5(2.72 \%)$ \\
\hline 4 & Brimolol & Brimolol & $1(0.54 \%)$ \\
\hline 5 & Timolol & Timolol & $25(13.59 \%)$ \\
\hline 6 & Bidine LS & Brimonidine & $7(3.80 \%)$ \\
\hline 7 & Bidine T & Brimonidine + timolol & $44(23.91 \%)$ \\
\hline 8 & Veldrop & Carboxymethylcellulose & $22(11.96 \%)$ \\
\hline 9 & Mannitol & Mannitol & $6(3.26 \%)$ \\
\hline 10 & Azopt & Brinzolamide & $2(1.09 \%)$ \\
\hline 11 & Travo & Travoprast & $1(0.54 \%)$ \\
\hline 12 & Acetazolamide & Acetazolamide & $24(13.04 \%)$ \\
\hline 13 & Bimatoprost & Bimatoprost & $1(0.54 \%)$ \\
\hline 14 & Lubrex & Carboxymethyl cellulolose & $3(1.63 \%)$ \\
\hline 15 & Latanoprost & Latanoprost & $1(0.54 \%)$ \\
\hline 16 & Gonfort & Bimatoprost + timolol & $10(5.43 \%)$ \\
\hline
\end{tabular}




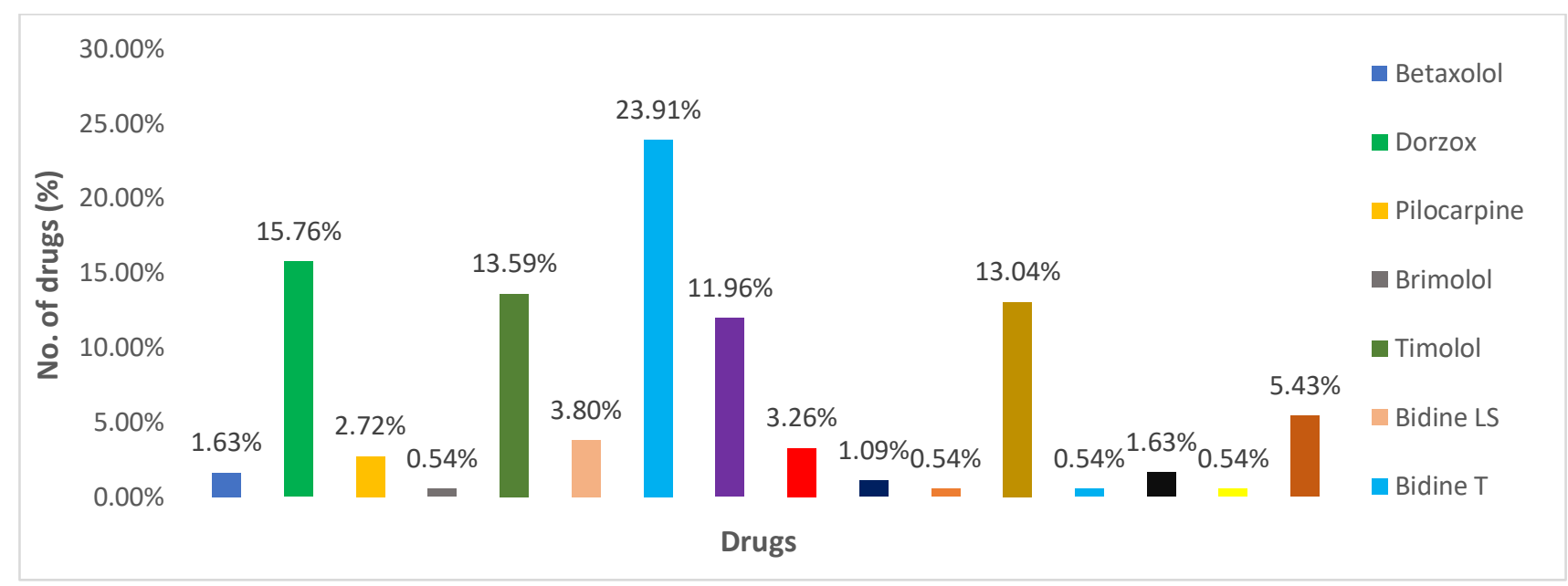

Figure 4: Drugs prescribed for glaucoma

\section{Prescribing pattern of drugs (Monotherapy) for glaucoma}

By analysing the prescription pattern of glaucoma patients, the most commonly drugs (monotherapy) were dorzolamide $(22.31 \%)$ which belong to the category of carbonic anhydrase as shown in table 5 \& figure 5 .

Table 5: Prescribing pattern of drugs (Monotherapy) for glaucoma

\begin{tabular}{|l|l|}
\hline Drug name & \% of total single drugs (n=130) \\
\hline Brimonidine & $7(5.38 \%)$ \\
\hline Dorzolamide & $29(22.31 \%)$ \\
\hline Betaxolol & $3(2.31 \%)$ \\
\hline Pilocarpine & $5(3.85 \%)$ \\
\hline Brimolol & $1(0.77 \%)$ \\
\hline Timolol & $25(19.23 \%)$ \\
\hline Brinzolamide & $2(1.54 \%)$ \\
\hline Travoprost & $1(0.77 \%)$ \\
\hline Acetazolamide & $24(18.46 \%)$ \\
\hline Bimatoprost & $1(0.77 \%)$ \\
\hline Latanoprost & $1(0.77 \%)$ \\
\hline Mannitol & $6(4.61 \%)$ \\
\hline Carboxymethylcellulose & $25(19.23 \%)$ \\
\hline
\end{tabular}

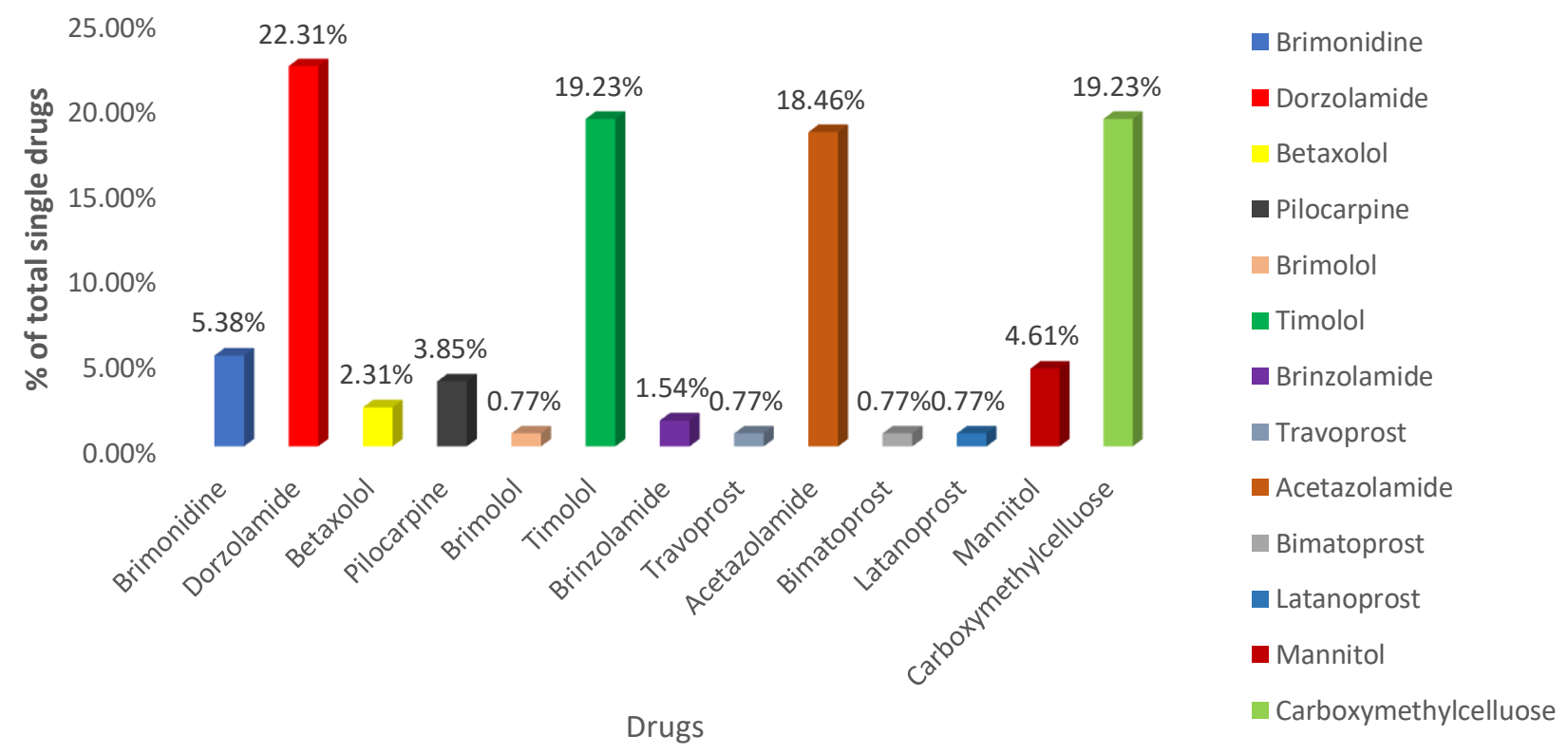

Figure 5: Prescribing pattern of drugs (monotherapy) for glaucoma 


\section{Prescribing pattern of drugs (combination therapy) for glaucoma}

The most commonly combination drug were Brimonidine+ timolol (79.63\%) followed by Bimatoprost+ timolol $(20.37 \%)$ as shown in table 6 \& figure 6 .

Table 6: Prescribing pattern of drugs (combination therapy) for glaucoma

\begin{tabular}{|l|l|}
\hline Drug name & $\begin{array}{l}\text { \% of total combination } \\
\text { drugs (n=54) }\end{array}$ \\
\hline Brimonidine+ timolol & $44(81.48 \%)$ \\
\hline Bimatoprost+ timolol & $10(18.52 \%)$ \\
\hline
\end{tabular}

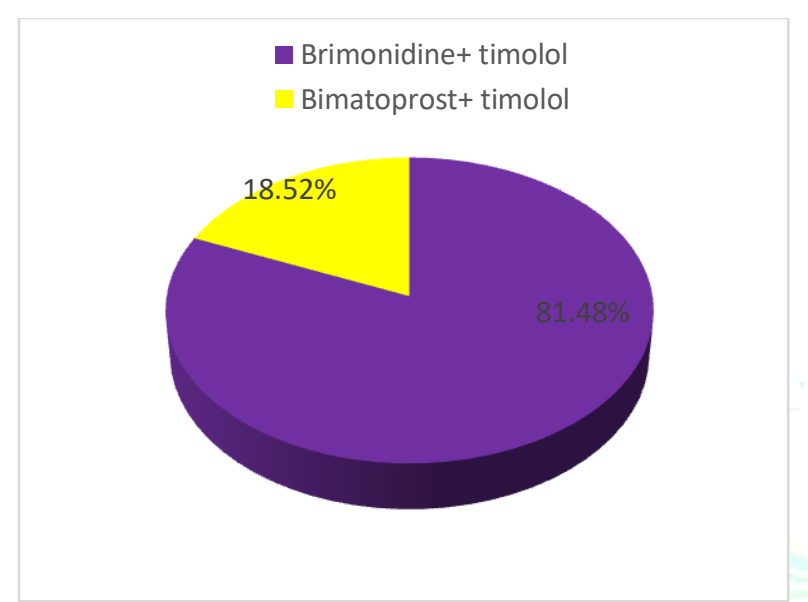

Figure 6: Prescribing pattern of drugs (combination therapy) for glaucoma

5. Average no. of drugs prescribed per prescription

Among 105 patients, two drugs (44.76\%) per prescription were mostly prescribed and average no of drug per prescription was 1.75 as shown in table $7 \&$ figure 7 .
Table 7: Average no. of drugs prescribed per prescription

\begin{tabular}{|l|l|}
\hline $\begin{array}{l}\text { Number of drugs per } \\
\text { prescription }\end{array}$ & $\begin{array}{l}\text { Number of prescriptions (\%) } \\
(\mathbf{n = 1 0 5 )}\end{array}$ \\
\hline One & $42(40 \%)$ \\
\hline Two & $47(44.76 \%)$ \\
\hline Three & $16(15.23 \%)$ \\
\hline
\end{tabular}

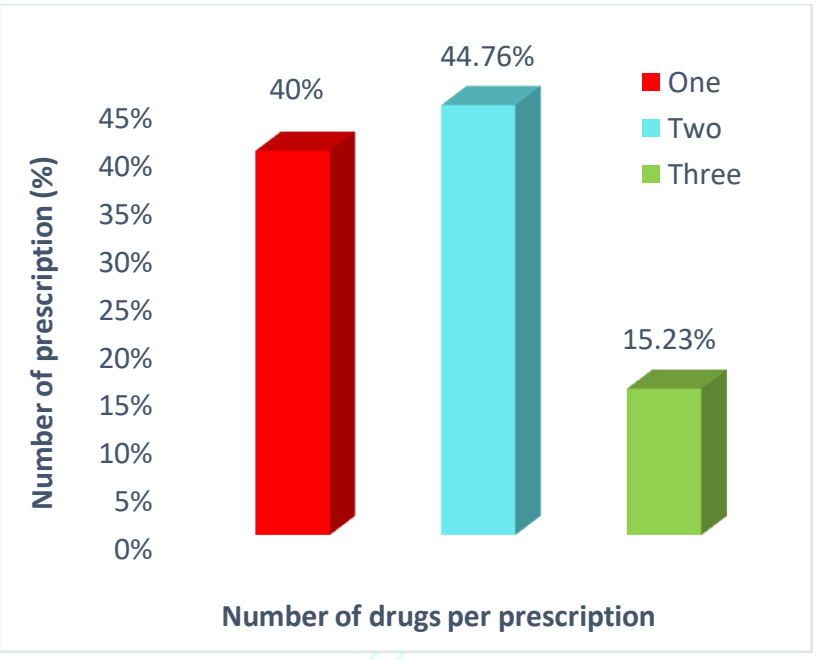

Figure 7: Average no. of drugs prescribed per prescription

\section{Category wise identification of drugs prescribed}

Out of 214 drugs, $32.24 \%$ were $\beta$ - blockers followed by $25.70 \%$ carbonic anhydrase, $23.83 \%$ alpha 2 agonists, $11.68 \%$ cellulose derivatives, $2.80 \%$ osmotic diuretics, $2.34 \%$ cholinergic agonists \& $1.40 \%$ prostaglandin analogues as shown in table 8 \& figure 8 .

Table 8: Category wise identification of drugs prescribed

\begin{tabular}{|l|l|}
\hline Drug Category & $\begin{array}{l}\text { No. of drugs (\%) } \\
\text { (n=184) }\end{array}$ \\
\hline$\beta$ - blockers & $55(29.89 \%)$ \\
\hline Carbonic anhydrase & $55(29.89 \%)$ \\
\hline Prostaglandin analogues & $8(4.35 \%)$ \\
\hline Alpha 2 agonists & $30(16.30 \%)$ \\
\hline Cholinergic agonists & $5(2.72 \%)$ \\
\hline Osmotic diuretics & $6(3.26 \%)$ \\
\hline Cellulose derivatives & $25(13.59 \%)$ \\
\hline
\end{tabular}




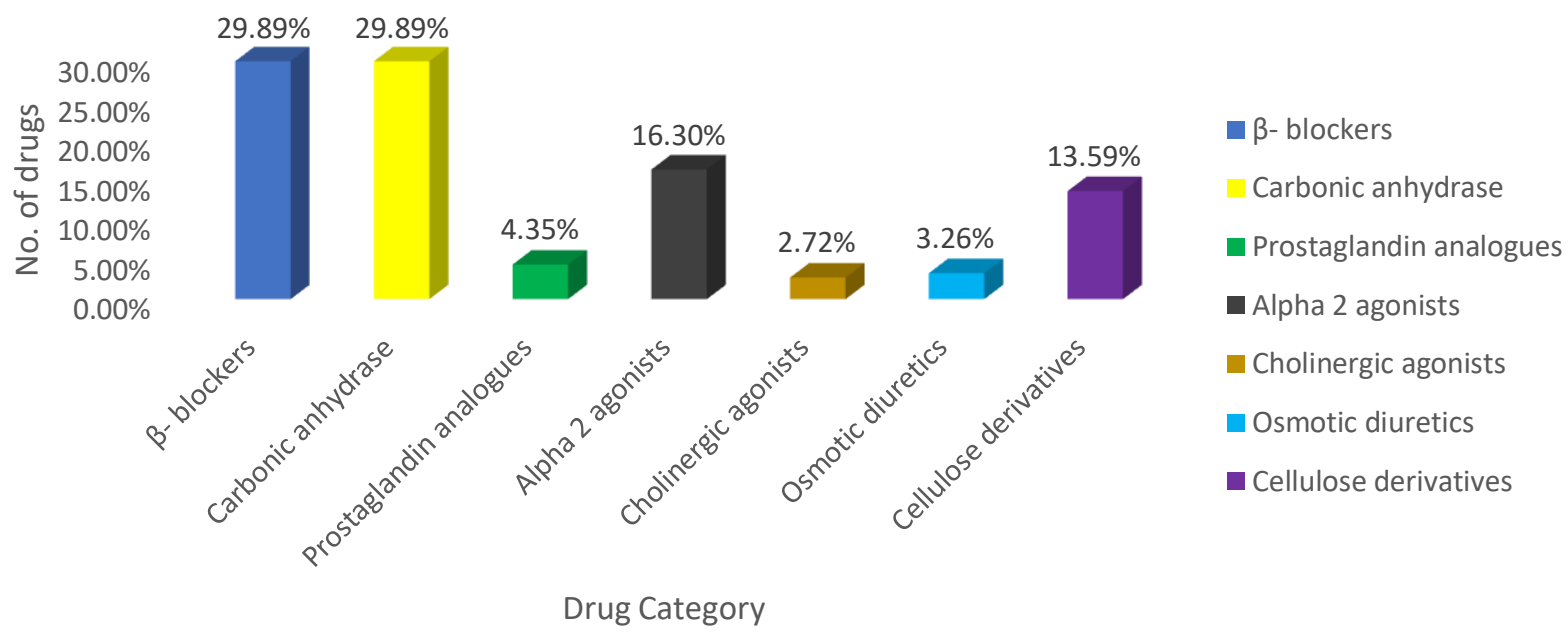

Figure 8: Category wise identification of drugs prescribed

\section{Comparison between monotherapy vs combination therapy}

Present study revealed that most of the patients were treated with combination therapy $(60 \%)$ followed by monotherapy (40\%) as shown in table 9 \& figure 9.

Table 9: Comparison between monotherapy vs combination therapy

\begin{tabular}{|l|l|l|}
\hline Therapy & $\begin{array}{l}\text { No. of patients } \\
(\mathbf{n = 1 0 5})\end{array}$ & Percentage (\%) \\
\hline Monotherapy & 51 & $48.57 \%$ \\
\hline Combination therapy & 54 & $51.43 \%$ \\
\hline
\end{tabular}

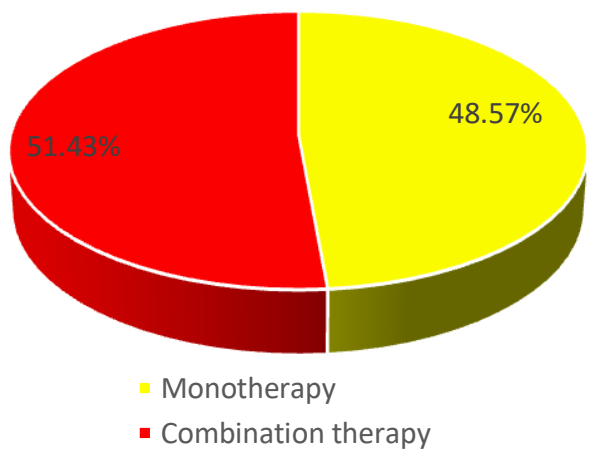

Figure 9: Comparison between monotherapy vs combination therapy

8. Distribution of anti-glaucoma drugs prescribed by generic and brand name.

Out of 105 patients, majority of drugs were prescribed by generic name $(73.33 \%)$ followed by brand name $(26.66 \%)$ as shown in table 10 \& figure 10 .

Table 10: Distribution of anti-glaucoma drugs prescribed by generic and brand name.

\begin{tabular}{|l|l|}
\hline Drugs & Number of patients (\%) \\
\hline
\end{tabular}

\begin{tabular}{|l|l|}
\hline & $\mathbf{( n = 1 0 5 )}$ \\
\hline Generic & $77(73.33 \%)$ \\
\hline Brand & $28(26.66 \%)$ \\
\hline
\end{tabular}

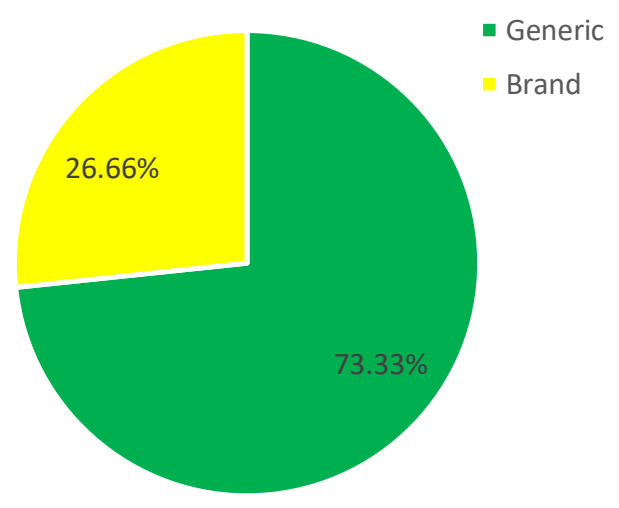

Figure 10: Distribution of anti-glaucoma drugs prescribed by generic and brand name

\section{DISCUSSION}

The following discussion is based on the data collected from a prospective study conducted on 105 patients of glaucoma. Different anti glaucoma drugs are prescribed in the clinical practice for the treatment of glaucoma. Pharmacologically these drugs are categorized in two classes -1 . reduction of aqueous humor secretion, 2. enhancement of aqueous outflow. The drug categories include, parasympathomimetic, carbonic anhydrase inhibitors (CAI's), $\alpha$-agonists, $\beta$ - blockers and Prostaglandin analogues. Drug utilization studies are routinely carried out to promote rational use of drug and it also prevents unnecessary drug use, expense \& potential hazards.

In the present prospective study on drug utilization pattern of glaucoma medication, out of 105 glaucoma patients, Open angle glaucoma is prevalent in $95.23 \%$ patients followed by $4.76 \%$ in closed angle glaucoma respectively this study is similar to the study Lulu Bahiyya U.I et al in which out of 
222 glaucoma patients, Open angle glaucoma is prevalent in $91 \%$ patients followed by $7 \%$ in closed angle glaucoma and $2 \%$ in Normal tension glaucoma respectively [7].

In the present study $64.76 \%$ were male \& $35.24 \%$ female and this finding is quite similar to the study of Patel B. Kaushal et al which showed that out of total 101 patients, 71 were males (70.29\%) and 30 were females (29.70\%). [8]

Maximum patients were in the age group of 46- 60 which also encountered in study by Ahmed Q S. et al in which out of 170 patients, all patients are divided into three age groups, 1) <40yrs 2) 40-60 yrs 3) >60 yrs. Maximum patients 94 $(55.29 \%)$ were between the age group of $40-60 \mathrm{yrs}$. In this age group $62(65.95 \%)$ were female while $32(34.04 \%)$ were male. [9].

Most commonly, two number of drugs per prescription $(44.76 \%)$ was prescribed and average no. of drug per prescription was 1.75 . The same study shown by Latha $\mathrm{C}$ Deepa et al which showed that out of total 50 prescriptions, the average number of drugs per prescription was 2.02[1], Patel B. Kaushal et al which showed that out of total 101 patients, average number of drugs per prescription was 2 (45\%) which includes Tab. Acetazolamide and Bimatoprost drops (19\% of Patients), Brimonidine Drops and Betaxolol Drops (13\% of patients) Tab. Acetazolamide and Pilocarpine drops (4\% of Patients) [8] \& Mahajan $\mathrm{H} \mathrm{M}$ et al showed that out of 405 record assessed, average number of drugs per prescription was 1.8. [10]

Our study show $48.57 \%$ patients received monotherapy which is quite similar to study by Rai $\mathrm{S}$ et al in which monotherapy was prescribed to 48 patients $(64.86 \%)$ [11] \& out of 184 drugs, total no of 130 drugs were prescribed in monotherapy \& most frequently prescribed group of drugs came out to be carbonic anhydrase inhibitors (29.89\%) which is different from the study by Nazia P et al which analysed out of 116 glaucoma patients, amongst the medications, beta blockers were prescribed the most (38.12\%), followed by carbonic anhydrase inhibitors (both oral and topical) and prostaglandin F2 $\alpha$ analogues $(14.36 \%$ each). The less commonly prescribed medicines were $\alpha 2$ agonists, cholinergic drugs, glycerol and antimicrobials [12].

Among all carbonic anhydrase inhibitors most commonly prescribed drug was dorzolamide (22.31\%) followed by acetazolamide (18.46\%) and brinzolamide (1.54\%). This study is different from the study by Advani M. et al in which dorzolamide, a topical carbonic anhydrase inhibitor was the second most common drug prescribed in present study (23\%) of which $15 \%$ was with timolol as FDC and the remaining (8\%) in combination with brimonidine [13].

After that, $\beta$ - blockers were prescribed mostly in which timolol was most frequently prescribed drug (19.23\%) as also noted by Rai $\mathrm{S}$ et al in which out of 74 case records, most commonly prescribed topical medication was timolol $0.5 \%$ solution $(29.16 \%)$ followed by bimatoprost $0.03 \%$ solution (20.83\%) [11] \& Yadav A. K et al in which out of total 297 drugs prescribed, timolol was found to be the most frequently prescribed drug constituting $82.22 \%$ of total prescriptions. [14]

Alpha 2 agonists (brimonidine, brimolol) formed 16.30\%, prostaglandin analogue (travoprost, Bimatoprost, latanoprost) formed 4.35\%, cholinergic agonists (pilocarpine) formed 2.72\%, osmotic diuretics (mannitol) formed $\quad 3.26 \% \quad \& \quad$ cellulose derivatives (carboxymethylcellulose) formed $13.59 \%$ of total prescriptions.
Out of 105 patients, $51.43 \%$ patients (54 patients) received combination therapy. This study is quite similar to study by Ahmed Q S. et al in which combination therapy was prescribed to 53 patients (45.69\% of total prescriptions) [9]. In combination therapy, out of 184 drugs only 54 drugs were prescribed in combination drug in which Brimonidine+ timolol (81.48\%) was most common prescribed drug which is similar to study by Patel B. Kaushal et al in which most commonly used fixed dose combination was Brimonidine + Timolol which was used in $87(86.1 \%)$ of patients [8] different from study by Yadav A. K et al in which Timolol and acetazolamide $(17.22 \%)$ was most commonly prescribed drug combination followed by timolol and dorzolamide (9.44\%) [14] followed by Bimatoprost+ timolol (18.52\%).

In the present study $73.33 \%$ of the drugs were prescribed by generic name while $26.66 \%$ were prescribed by their brand names which is higher than $0-10 \%$ as reported by other Indian studies such as Lulu Bahiyya U.I et al in which ${ }^{[7]}$ and Ahmed Q S. et al [9] in which 100\% drugs were prescribed by brand names.

In the present study $73.33 \%$ of the drugs were prescribed by generic name while $26.66 \%$ were prescribed by their brand names which is higher than $0-10 \%$ as reported by other Indian studies such as Lulu Bahiyya U.I et al in which [7] and Ahmed Q S. et al [9] in which $100 \%$ drugs were prescribed by brand names.

\section{CONCLUSION}

From the study conducted at Shri Mahant Indiresh Hospital, monotherapy with dorzolamide was the first line choice for glaucoma and timolol was found to be the second line choice. Most of the fixed drug combinations found were brimonidine+ timolol. The prescription analysis showed that most of the drugs were prescribed in their generic name. From the study, it is evident that the male populations are more prone to glaucoma as compared to female. Open angle glaucoma is prevalent in $95.23 \%(n=100)$ patients than Angle closure glaucoma and mostly affected age group was between 46-60 years. Out study indicates that generic names were mostly prescribed then brand names. So, less awareness is required related to generic drug prescription. These findings vary from region to region, no generalization can be made. However, these inferences may provide a lead for monitoring rational drug usage. For glaucoma whatever therapy is chosen, the concept to be kept in mind is that glaucoma therapy is lifelong and needs consideration of cost-effectiveness and convenience in individual patient. There is need to conduct many such studies at regular interval at our institute and also at other institutes across the India. This is useful for auditing large number of prescriptions to find out early signals of the irrational drug use. Such study should be followed by education of the prescribers on rational drug therapy for benefits and safety of the patients. This study provided a general insight into the prescribing patterns of ophthalmological products in Dehradun (Uttarakhand). Polypharmacy is not seen, and prescription errors were minimum in our study which concludes with overall impression of rational prescription. Thus, periodical auditing of the prescriptions will help to measure the impact of the intervention on the prescribing pattern and improve rational pharmacotherapeutics. It is essential to conduct similar study in future to elucidate rational prescribing for treatment of Glaucoma. 


\section{REFERENCES}

1. Deepa Latha C, Leela Pratyusha, "To Study the Drug Use Pattern in Primary Open-Angle Glaucoma in a Tertiary Care Teaching Hospital", Asian Journal of Pharmaceutical and Clinical Research, 2017, 10(2), 198-200.

2. David A. Lee and Eve J. Higginbotham, "Glaucoma and its treatment: A review", American Society of Health-System Pharmacists, 2005, 62.

3. Robert N. Weinreb, Tin Aung and Felipe A. Medeiros, "The Pathophysiology and Treatment of Glaucoma: A Review", JAMA, 2014, 311(18), 1901-1911.

4. file:///C:/Users/Microsoft/Desktop/article\%20dus/PatientG uide.pdf. Assessed on Dec 08.

5. Hardik V Vaniya1, Nishita H Darji, Vikas R Patel, Devdatta J Gohel, "Drug Utilization Study in Ophthalmology Outpatients in a Tertiary Care Hospital", Advances in Pharmacology and Pharmacy, 2016, 4(2), 11-15.

6. Amit Kumar Jain, Seema Jain, Vikrant Sharma, Dadan Ji Pandey, Anand Shukla, "Drug Utilization Study in Ophthalmology Outpatient Department in a Tertiary Care Teaching Hospital of Western Uttar Pradesh, India", Asian Journal of Pharmaceutical and Clinical Research, 2016, 9(1), 354-356.

7. Lulu Bahiyya U.I, Sreeja P.A, "Prevalence of Glaucoma \& Its Drug Utilization Pattern in Eye Care Hospitals, Palakkad- A Prospective Study", International Journal of Current Medical and Pharmaceutical Research, 2017, 3(5), 1751-1753.

8. Kaushal B. Patel, Gurusharan H. Dumra, Adarsh Jeet Singh, Abhishek Vyas, Chetan G. Parmar, "A Drug Utilization Study in Glaucoma Patients in Ophthalmology Outpatient Department in a Tertiary Care Hospital", International Journal of Basic \& Clinical Pharmacology, 2017, 6(8), 1955- 1958.
9. Quazi Shahir Ahmed, Kauser Sayedda, Akhil Agarwal, NA Ansari, "Drug Utilization Study of Antiglaucoma Drugs In A Tertiary Care Teaching Hospital, Bareilly", World Journal of Pharmaceutical research, 2014, 3(2), 2420-2428.

10. H M Mahajan, R Honrao, A S Borkar, R T Badwaik, Chopade S S, P Surwase, "A Drug Utilization Study in Glaucoma Patients in a Tertiary Care Hospital of Central India", Journal of Contemporary Medicine and Dentistry, 2015, 3(2), 44-47.

11. Seema Rai, Seemee Khilji, Lavanya G Rao, Puneet Hegde, Sarita R J Gonsalves, Tara V Shanbhag, "Prescribing pattern and adverse events of drugs used in patients with primary open-angle glaucoma (POAG) attending a tertiary care hospital: Retrospective study", National Journal of Physiology, Pharmacy and Pharmacology, 2017, 7(2), 189-193.

12. Nazia Parween, Surabhi Gupta, Sanjiv Kumar, Kirti Jain, P. P. Khosla, Saurabh Kansal, Wase Khan, "Drug Utilization Study in Primary Glaucoma Patients Attending the Ophthalmology Outpatient Department of a Tertiary Care Hospital in Western Uttar Pradesh", Delhi Journal of Ophthalmology, 2017, 28, 2529.

13. Manjari Advani, Trupti Jadhao, "Study of prescription pattern of antiglaucoma drugs used in treatment of primary open angle glaucoma in ophthalmology outpatient department of a tertiary care hospital", International Journal of Basic \& Clinical Pharmacology, 2018, 7(11), 2228-2233.

14. Arvind Kumar Yadav, Varsha Patel, "Drug use in primary open angle glaucoma: A prospective study at a tertiary care teaching hospital", Indian Journal of Pharmacology, 2013, 45(2), 117-120. 